\title{
TIKUNA, Djuena. Tchautchiüãne. Direção geral: Djuena Tikuna e Diego Janatã. Gravação: José Maria Medeiros (Estúdio 301). Manaus, 2017. 1 CD (57 min)
}

\author{
Agenor Cavalcanti Vasconcelos Neto* \\ * Universidade Federal do Amazonas - Manaus, AM, Brasil \\ Doutorando em Antropologia Social (bolsista Capes) \\ agenor7@hotmail.com \\ https://orcid.org/0000-0002-6611-5017 \\ Patrícia Vaz Borges ${ }^{* *}$ \\ ** Universidade Federal do Amazonas - Manaus, AM, Brasil \\ Graduanda em Comunicação Social - Jornalismo \\ patvazborges@gmail.com \\ https://orcid.org/0000-0001-9924-6454
}




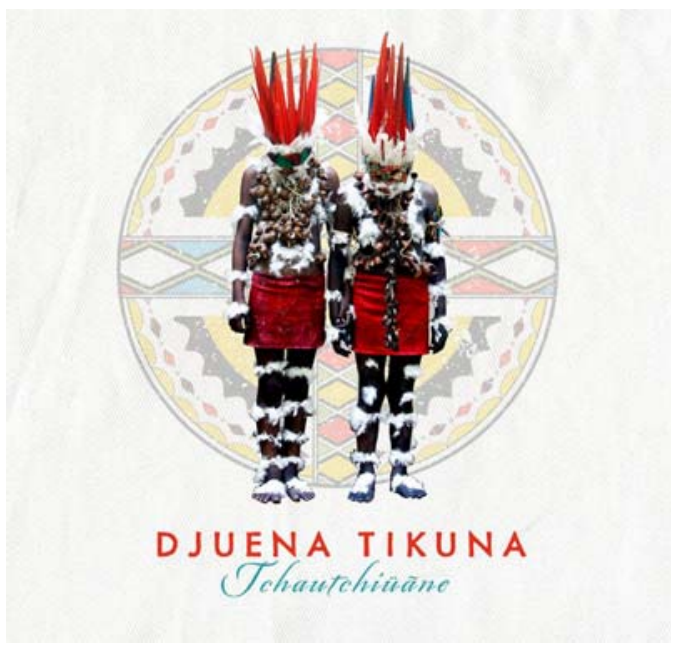

Capa do CD Tchautchiüãne.

Tchautchiüãne ("minha aldeia", tradução livre) é o título do primeiro disco da cantora indígena Djuena Tikuna, ${ }^{1}$ lançado em 2017 no palco do Teatro Amazonas, em Manaus. Em 23 de agosto, a artista convidou alguns "parentes" e apresentou o primeiro espetáculo com protagonismo indígena, tanto no palco, como na produção artística e executiva, ao longo dos 120 anos de existência do aclamado teatro. Djuena explica o papel da música na sua vida:

A música para nós, povos indígenas, é nativa. É nativa porque nasce conosco, tem cheiro de fumaça, gosto de mapati e é pintada de urucum e jenipapo. Esse é o meu primeiro $\mathrm{CD}$ solo e foi produzido com muito carinho e cuidado. As músicas, os arranjos, as letras e tudo o que queremos colocar no disco foram muito bem pensados. ${ }^{2}$

O CD Tchautchiüãne não está preso ao conceito de "tradicional"; buscando inspiração nos cantos dos antigos, apresenta uma nova geração de indígenas que compõe seus próprios cantos. Muitas músicas do CD são assinadas por Djuena em parceria com seus familiares: seu marido, Diego Janatã, e seus irmãos, Poramecü Tikuna e Anderson Tikuna.

Através de suas composições, em Tchautchiüãne Djuena entoa o canto sagrado do povo Magüta do Alto Rio Solimões. Com todas as 12 faixas cantadas em língua

1 Os Tikuna possuem uma larga parceria com a antropologia no Brasil. Há 30 anos, trabalhos iniciados com João Pacheco de Oliveira (1986) são referências fundamentais sobre o povo no Museu Nacional do Rio de Janeiro. Pacheco também orientou outras pesquisas, como por exemplo a de Edmundo Pereira (1999) que possui trabalhos específicos sobre a música tikuna.

2 Depoimento recolhido em entrevista de campo, Manaus, agosto de 2017; demais falas de Djuena Tikuna sem indicação de referência provêm dessa mesma entrevista. 
tikuna, sendo a última uma versão do Hino Nacional Brasileiro, o disco celebra, segundo a cantora e compositora, "a floresta, a ancestralidade e a resistência cultural indígena". Explica Djuena: "Esse é o compromisso que assumo com a música. Divulgar nossa cultura, nossa língua, nossa resistência cultural." A cantora representa o grupo indígena mais populoso do Brasil, e a produção e projeto do disco se misturam com a militância do movimento indígena. A última página do encarte do disco é uma reivindicação à garantia da demarcação das terras indígenas.

Ao falar sobre o CD, Djuena definiu sua música como "música popular indígena", segundo ela, "para deixar claro que não é 'ritual tradicional', mas é música tikuna". De todo modo, a capa do seu disco é a fotografia de uma imagem clássica do ritual mais conhecido e pesquisado entre os Tikuna, o ritual da moça nova. Dois indígenas mascarados trazem à capa do disco um tom ritual, mágico. Além do nome da cantora, escrito em cor vermelha disposto entre a fotografia e o nome do disco, grafado em língua indígena, não há nada mais que remeta à imagem da cantora. Seu rosto está na contracapa. Esse fato mostra o repertório simbólico do artista indígena contemporâneo, representado por Djuena, ligado aos elementos conceituais que formam a ética e a estética do arcaico "tradicionalismo", posto a partir do modelo dado pelas fotografias antropológicas de décadas atrás.

A faixa inicial escancara uma realidade antiga: o desrespeito à floresta, aos rios e aos animais. "Yiemagü rü nainecüti' igü" ("nós somos a floresta", em tradução de Djuena) enfatiza, em sua letra, os impactos da destruição ambiental e a preocupação dos povos indígenas quanto a isso. Diferentemente de como nos relacionamos com nossa cidade, Djuena canta que não só faz parte da floresta, mas que ela própria é floresta e se dispõe a lutar para defendê-la. O CD expressa o pensamento ameríndio na relação marcante que há entre a floresta e a essência da vida humana, compartilhando um mesmo espírito, noção muito trabalhada recentemente por teorias antropológicas como o perspectivismo (Viveiros de Castro, 2015) e novo animismo (Descola, 1992).

As letras abordam uma forte relação com sua ancestralidade, e ela faz da música e do disco instrumentos para registrar, divulgar e imortalizar os conhecimentos adquiridos com sua avó e os anciãos tikuna. Como já mencionado, repleto de reivindicação político-cultural, o disco também chama atenção para as questões da demarcação dos territórios indígenas no Brasil de 2017, onde uma proposta de emenda à Constituição brasileira poderia pôr a perder grande parte dos direitos indígenas aos seus territórios tradicionais. “É preciso fazer 
frente a essas ameaças. Porque quem poderá lutar por nós, se não formos nós mesmos?", argumenta Djuena. Em "Eware" (terra natal mitológica dos Tikuna), segunda faixa, destaque-se o relacionamento que há na cosmologia indígena tikuna entre a terra, onde nasceram os primeiros ancestrais tikuna, e a dimensão do sagrado. Segundo Djuena,

Tchautchiuiãne é o sentimento de também pertencer a uma aldeia maior em que todos nós somos parentes, como os pássaros multicoloridos cantando em revoada. O nosso canto vem do tempo dos antigos, fazemos parte do caminho, para que novas gerações continuem a sua cantoria.

Além de toda poesia nas letras, os arranjos melódicos e percussivos das canções se destacam. Na maioria das músicas a base é dada pelo "bocó de giro", instrumento orgânico criado pelo percussionista amazonense Eliberto Barroncas e que dá um "tom" de espiral, de circularidade às músicas, o que remete a sonoridade a mantras. Nas faixas que reverenciam festas e união, como em "Maraka'anandê" ("a festa dos nossos maracás"), com participação de Marlui Miranda, e em "Maîyu wüiguü" ("somos parentes"), a musicalidade é mais dançante, algo como forró, e expressa alegria e celebração.

Além de Eliberto (percussão) também participaram da gravação os músicos Poramecü Tikuna (maracá e voz), Anderson Tikuna (violão), ambos irmãos de Djuena, como já dito, o espanhol Antón Carballo (violino), Diego Janatã (percussão e flautas), Agenor Vasconcelos (contrabaixo), Abner Viana (clarinete) e Cleudilon Passarinho (sons de pássaros).

O disco foi gravado e mixado no estúdio 301, em Manaus, por José Maria Medeiros, exceto a voz de Marlui Miranda na faixa "Maraka'anandê", gravada e mixada no estúdio A9, em São Paulo, por Apollo Carvalho. O encarte do álbum traz belas fotos do, também fotógrafo, Diego Janatã. A direção de arte é assinada por Djuena Tikuna, Felipe Lobo e Diego Janatã. O projeto gráfico é de Felipe Lobo.

Sobre sua relação com a música, Djuena diz ser algo natural, que faz parte do cotidiano indígena, mas a oportunidade ${ }^{3}$ de gravar seus cantos surgiu há pouco tempo, por isso precisou dedicação ao pensá-los e produzi-los para

3 O disco foi financiado com o Programa de Apoio às Artes da Secretaria de Cultura do Estado do Amazonas. 
gravar. A música de Djuena mantém um elo vivo com os ancestrais do seu povo: “O que sei é que a música para nós, povos indígenas, é nativa, tanto quanto o mais velho ancião" (cf. Medeiros, 2016).

O CD foi produzido em família. A parte fonográfica e gráfica ficou a cargo do marido de Djuena, Diego Janatã, ao passo que ela articulou todos os patrocínios e parcerias necessárias para a gravação e do show de lançamento. Foi emocionante ver e ouvir o Teatro Amazonas lotado de representantes dos povos indígenas. Assim como no palco, também no CD Djuena costura e tece seu repertório com a ajuda de irmãos, irmãs, cunhados e amigos parceiros locais que se articulam pelo interesse na música indígena.

O método de gravação do disco dispensou a receita dos produtores musicais e foi gravado inteiramente "à capela", sem instrumento para referência harmônica que pudesse "guiar" Djuena. A voz afinada, agradável e descansada para as gravações não está guiada ao princípio de tonalidade da música ocidental. A produção do disco recria o encontro entre o pensamento indígena e a música do outro, articulando de forma artística várias noções sobre música. É possível encontrar entre os convidados músicos eruditos, populares, profissionais e amadores.

Djuena combina arte tikuna a influências da world music. Ela tem se destacado no cenário nacional com participações em eventos como a Rio+20, Femucic (Festival da Cidade Canção de Maringá - PR), entre outras apresentações em eventos indígenas, como nas assembleias das organizações e mostras culturais. No início de 2018, o CD foi indicado na maior premiação musical indígena do mundo, que acontece anualmente no Canadá, o Indigenous Music Awards.

Por onde a gente tem passado o público tem aceitado bastante. As pessoas gostam da sonoridade dos instrumentos orgânicos que fazemos. Valorizam muito as coisas da Amazônia, mas é importante valorizar as pessoas também. A gente vai quebrando com os paradigmas do exótico, do bom selvagem. Índio não quer apito, índio quer é a demarcação de suas terras, o respeito ao seu modo de vida, a sua cultura, uma educação diferenciada e de qualidade. (cf. Brasil, 2017).

O CD Tchautchiüãne pode ser conferido inteiramente no perfil de Djuena no SoundCloud, por meio do endereço eletrônico: https://soundcloud.com/user972078432-606286737. Segundo Djuena Tikuna, sua música atualiza o caminho musical deixado por seus antepassados. Djuena sempre repete que seus 
cantos são o caminho que seus avó deixaram, ela continua caminhando por essa trilha do tempo em que a música é o elo entre as geração passadas e as gerações vindouras de indígenas tikuna. No Brasil, essa relação da música com um caminho que organiza a memória pode ser encontrada em inúmeros outros trabalhos artísticos de grupos indígenas e também é destacada por antropólogos que se dedicaram a escrever sobre o tema; vale a pena conferir, por exemplo, a resenha de Deise Lucy Oliveira Montardo (1999) sobre o Ñande reki arandu, autoria de Mano Penna.

\section{Referências}

BRASIL, K. Cantora Djuena Tikuna lançará o primeiro CD e quer índios na plateia do Teatro Amazonas. Amazônia Real, Manaus, 7 jul. 2017. Disponível em: http://amazoniareal.com.br/cantora-djuena-tikuna-lancara-primeiro-cd-e-quer-indios-na-plateia-do-teatro-amazonas. Acesso em: 14 dez. 2017.

DESCOLA, P. Societies of nature and the nature of society. In: KUPER, A. (ed.). Conceptualizing society. London: Routledge, 1992. p. 107-126.

MEDEIROS, J. O que assobiava Y'oi quando pescou o povo Tikuna?. Farofafá. São Paulo, 2 out. 2016. Disponível em: http://farofafa.cartacapital.com.br/2016/10/02/o-que-assobiava-yoi-quando-pescou-o-povo-tikuna/. Acesso em: 14 dez. 2017.

MONTARDO, D. L. O. Ñande Reko Arandu: memória viva guarani. Horizontes Antropológicos, Porto Alegre, ano 5, n. 11, p. 203-205, out. 1999.

OLIVEIRA, J. P. de. Fricção interétnica. In: OLIVEIRA, J. P. de. (org.). Dicionário de ciências sociais. Rio de Janeiro: Fundação Getúlio Vargas, 1986. p. 495-498.

PEREIRA, E. Reorganização social no Noroeste do Amazonas: elementos sobre os casos Uitoto, Bora e Ticuna. 1999. Dissertação (Mestrado em Antropologia Social) - Museu Nacional, Universidade Federal do Rio de Janeiro, Rio de Janeiro, 1999.

VIVEIROS DE CASTRO, E. Metafisicas canibais. São Paulo: Cosac Naify, 2015. 